\title{
Assessment of indoor radon levels in Portuguese thermal spas
}

\author{
A.S. Silva ${ }^{1,2 \star}$, M.L. Dinis ${ }^{1,2}$ and A.J.S.C. Pereira ${ }^{3}$ \\ 1 CERENA, FEUP/UPorto - Centre for Natural Resources and the Environment, Faculty of Engineering, University of Porto, R. Dr. Roberto \\ Frias, 4200-465, Porto, Portugal. \\ 2 PROA/LABIOMEP - Research Laboratory on Prevention of Occupational and Environmental Risks, Faculty of Engineering, University of \\ Porto, R. Dr. Roberto Frias, 4200-465, Porto, Portugal. \\ 3 CEMUC, Department of Earth Sciences, University of Coimbra, Rua Sílvio Lima, University of Coimbra - Polo II, $3030-790$ Coimbra, \\ Portugal.
}

Received 15 March 2016 - Accepted 12 Octobre 2016

\begin{abstract}
The concentration of radon was assessed in the indoor air of 14 thermal spas and in the home of a selected worker from each thermal spa. The measurements of the indoor radon concentration were carried out using CR-39 detectors, placed in both the workplaces and workers' homes, exposed for an average period of 45 days, in different seasons of the year. For the thermal spas, the indoor radon concentration ranged between 73 and $4335 \mathrm{~Bq} \mathrm{~m}^{-3}$, with a geometric mean of $445 \mathrm{~Bq} \mathrm{~m}^{-3}$ and an arithmetic mean of $687 \mathrm{~Bq} \mathrm{~m}^{-3}$, and within the workers' homes ranged between 68 and $4051 \mathrm{~Bq} \mathrm{~m}^{-3}$, with a geometric mean of $410 \mathrm{~Bq} \mathrm{~m}^{-3}$ and an arithmetic mean of $785 \mathrm{~Bq} \mathrm{~m}^{-3}$. The annual effective doses due to radon inhalation were calculated considering two different exposure scenarios for the thermal spas. For the worst-case scenario, assuming that workers do not have job rotation, the values varied between 1 and $31 \mathrm{mSv} \mathrm{y}^{-1}$, while for an exposure scenario considering job rotation, the calculated dose ranged between 0.6 and $16 \mathrm{mSv}^{-1}$. For workers' homes, the calculated dose ranged between 2 and $102 \mathrm{mSv} \mathrm{y}^{-1}$. The results showed that the EU reference level of $300 \mathrm{~Bq} \mathrm{~m}^{-3}$ (Directive 2013/59/EURATOM) was exceeded in several cases. In 36\% of the thermal spas the exposure of the workers is likely to exceed the effective dose of $6 \mathrm{mSv} \mathrm{y}^{-1}$ and in this case, according to the Directive, it should be considered as "a planned exposure situation".
\end{abstract}

Keywords: Radon / dose / occupational exposure / thermal spa

\section{Introduction}

Radon is a naturally occurring radioactive gas produced by the radioactive decay of radium-226, which is present in uranium ores, phosphate rocks, shales, and igneous and metamorphic rocks such as granite, gneiss and schist (Gray et al., 2009; Silva et al., 2013, 2014). It is recognized as the most significant natural source of human exposure, being identified by the World Health Organization as the second leading cause of lung cancer after tobacco smoke (UNSCEAR, 2000; OMS, 2007). It is also estimated that the risk of lung cancer increases by $16 \%$ per $100 \mathrm{~Bq} \mathrm{~m}^{-3}$ increase in the long-term average radon concentration (WHO, 2009). Therefore, the assessment of indoor radon levels is important from the point of view of radiological protection and public health (ICRP, 1994; WHO, 2009).

The recently published European Directive 2013/59/EURATOM suggests that Member States should establish national reference levels for indoor radon concentrations in

\footnotetext{
^ pee11022@fe.up.pt
}

workplaces. However, the reference level for the annual average activity concentration in air should not be higher than $300 \mathrm{~Bq} \mathrm{~m}^{-3}$, unless it is warranted by prevailing national circumstances; in this case, the Member State should submit the information to the European Commission. In Portugal, national legislation, DL 79/2006, defines the reference concentrations of pollutants within existing buildings, with a maximum concentration of $400 \mathrm{~Bq} \mathrm{~m}^{-3}$ for radon, monitoring only being mandatory in buildings located in granitic areas (Antão, 2014; Silva et al., 2016).

The main purpose of this work was to assess the concentration of indoor radon within both occupational and residential environments, and compare the results with the EU reference level and the national protection threshold by considering different workplaces in Portuguese thermal spas and workers' homes located in areas identified with potentially high levels of indoor radon.

The annual effective dose received by the workers considering both contributions was also assessed by the calculation of the inhalation dose. 


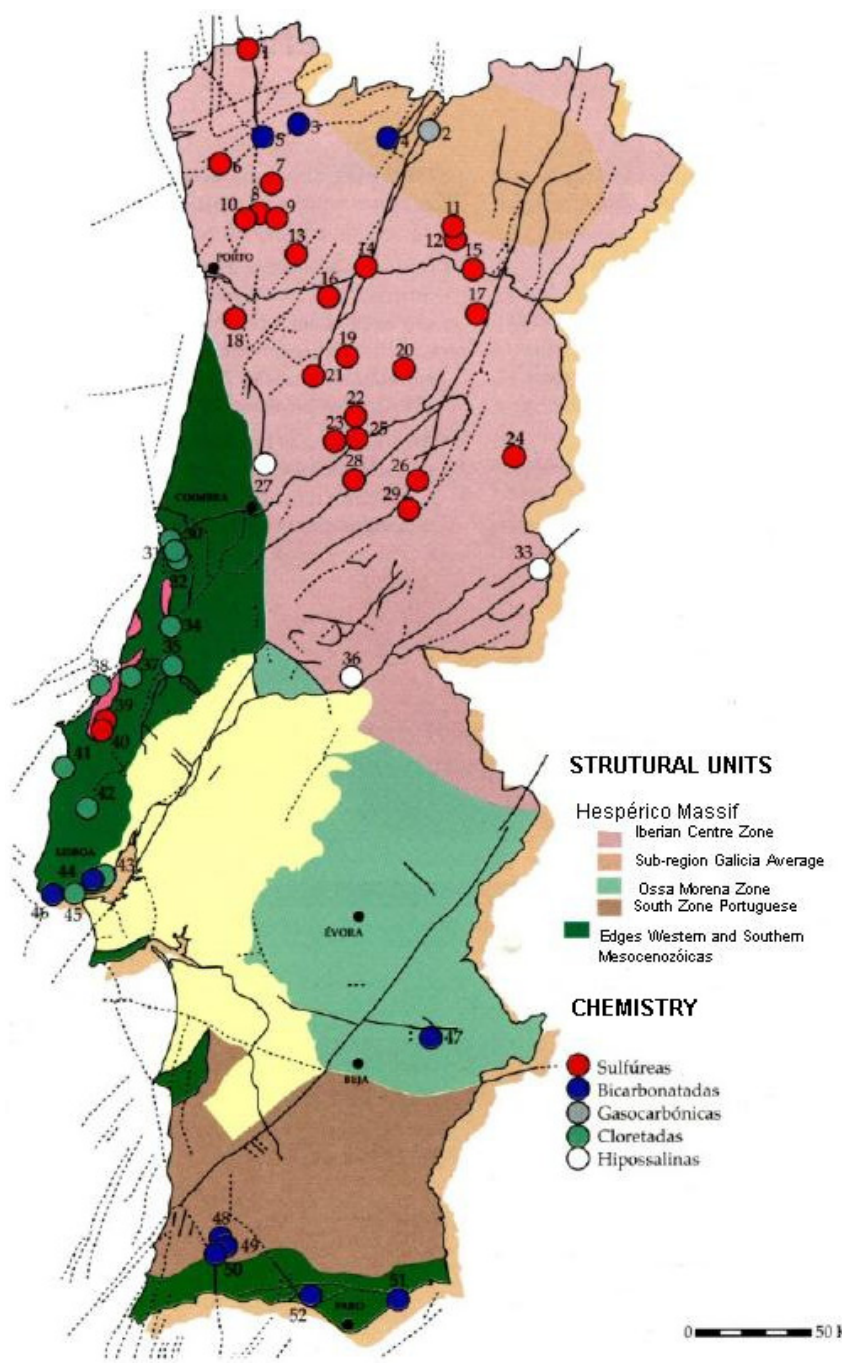

Figure 1. Thermal spas in Portugal.

\section{Methods}

Indoor radon monitoring was performed in 14 Portuguese thermal spas, which represent $41 \%$ of all existing thermal spas in Portugal. The majority of the spa establishments are located in the northern part of the country, where the geology comprises predominantly granite and other plutonic rocks (Figure 1). The presence of numerous joints and faults is closely related to the occurrence of thermal springs (Carvalho, 1996). Radon dissolved in water may enter the indoor air when water is used in thermal spas, and this was considered the main natural source of radon in this environment. For workers' homes, the source of indoor radon was considered to be subsoil and construction materials, as there is no usage of thermal water.

Indoor radon concentration measurements were conducted in different workplaces of each of the selected thermal spas (TSs) as no such measurements existed. A selected worker's home from each thermal spa was also monitored for the assessment of the radon concentration.

The spa facilities under study where the indoor radon was measured comprised treatment rooms, pools and some access spaces where workers remain during treatment sessions: the access corridor to the thermal pool (AC), pump room (PR), bathtubs (BT), spa hall (HS), jet shower (JS), leisure pool (LP), ORL, rest balcony (RB), sludge area (SA), steam hall (SH), treatment area (TA), thermal pool (TP), vapors (VP) and Vichy shower (VS).

Initially, it was intended to carry out indoor radon measurements for each thermal spa, in two different seasons (spring and fall or summer and winter), as the radon indoor concentration is indirectly affected by the weather of the location (besides other factors). Seasonal changes in the weather affect the ventilation pattern as well as the behavior of the occupants of buildings, such as turning on the mechanical ventilation and opening of windows or doors (Kobeissi et al., 2014). However, due to the seasonal operation of some of the thermal spas, it was necessary to adjust the measurement intervals to the operating period. Therefore, for each of the thermal spas the assessment included measurements in two different periods, between November 2013 and May 2015, through winter (WI), spring (SP), summer (SU) and fall (FA), with a few exceptions where radon measurements were carried out during only one period: TS4, TS5, TS6 and TS7. This was due to the fact that TS4 and TS7 are open only 3 months of the year, and TS5 and TS6 joined the study at a later stage. Also, although TS9 participated in the study, this establishment is closed to the public and therefore there are no workers using the thermal water.

Radon concentration measurements were carried out in twelve time intervals between 2013 and 2015 with an average duration of 45 days: period I, from $17 / 11 / 2013$ to 20/12/2013; period II, from $16 / 01 / 14$ to $03 / 03 / 2014$; period III, from $11 / 03 / 2014$ to $24 / 04 / 2014$ - mainly winter periods; period IV, from $13 / 05 / 2014$ to $27 / 06 / 2014$ - mainly a spring period; period V, from $12 / 06 / 2014$ to $22 / 07 / 2014$; period VI, from $03 / 07 / 2014$ to $13 / 08 / 2014$; period VII, from $31 / 07 / 2014$ to $10 / 09 / 2014$; period VIII, from $21 / 08 / 2014$ to $01 / 10 / 2014$ - mainly summer periods; period XI from 18/09/2014 to $31 / 10 / 2014$; period X, from $13 / 10 / 2014$ to $26 / 11 / 2014$ - mainly fall periods; period XI, from 02/12/2014 to 22/01/2015 mainly a winter period; and period XII, from $02 / 03 / 2015$ to $13 / 04 / 2015$ - mainly a spring period.

For each worker's home, the assessment was conducted in the living room and only for one single period of 42 days.

The measurements of radon concentrations in air were performed using CR-39 nuclear track detectors enclosed in small cylindrical diffusion chambers (5-cm height, $3-\mathrm{cm}$ diameter). These detectors comprise a small piece of polycarbonate, highly sensitive to ionizing particle tracks such as alpha particles. Quality assurance measures were followed to minimize further exposure of the detectors before and after usage.

The CR-39 detectors were placed in each room approximately 2 meters from the floor. At the end of each time period (on average 45 days) the detectors were removed and stored individually in sealed containers to prevent any contamination from other sources during transport to the laboratory (Silva and Dinis, 2016). The analysis was performed in the Natural Radioactivity Laboratory in the Department of Earth Sciences of the University of Coimbra.

At the laboratory, the detectors were etched in $25 \% \mathrm{NaOH}$ solution at $90{ }^{\circ} \mathrm{C}$ for $270 \mathrm{~min}$. The number of tracks in a $1-\mathrm{cm}^{2}$ area on each film was counted by an automated microscope 
reader. The background track density was subtracted and related to the radon concentration level using a calibration factor obtained by exposure of detectors of the same batch in a certified calibration chamber (Radosys, 2000).

In order to guarantee the quality of the results, a traceability system was set up for both sampling and measuring. Also, the laboratory takes part regularly in inter-comparison exercises with other laboratories in order to estimate the statistical uncertainty (analytical error less than $10 \%$ of the obtained value). The detection limit using the procedure described is $5 \mathrm{~Bq} \mathrm{~m}^{-3}$ (Madureira et al., 2016).

The results of the indoor radon concentration were compared with the EU reference level and the national protection threshold.

The annual effective dose due to inhalation of the indoor radon was calculated in both environments (occupational and residential) as a comparison baseline for the exposure in the workplaces and homes. In addition, the inhalation dose in the workplaces was compared with the EU reference level of dose exposure in existing exposure situations.

The inhalation dose $\left(D, \mathrm{mSvy}^{-1}\right)$ was calculated from the results obtained for the indoor radon concentration $\left(C_{R n}, \mathrm{~Bq} \mathrm{~m}^{-3}\right)$ and considering the following exposure parameters in indoor environments (ICRP, 1994; UNSCEAR, 2000): for the exposure time (ET), an occupancy of $2000 \mathrm{~h} \mathrm{y}^{-1}$ for the exposure within the thermal spas and an occupancy of $7000 \mathrm{~h} \mathrm{y}^{-1}$ for the exposure in the workers' homes, an equilibrium factor between radon and its progeny of 0.4 and a dose conversion factor of $9 \times 10^{-6}\left(\mathrm{mSv} \mathrm{y}^{-1}\right.$ per Bq m${ }^{-3}$ ) (effective dose received by adults per unit of ${ }^{222} \mathrm{Rn}$ activity per unit of air volume) (Eq. (1)):

$$
D=C_{R n} \times 0,4 \times E T \times 9 \times 10^{-6} .
$$

Although there is job rotation in all the thermal spas (with the exception of TS8), the dose was assessed considering the "worst-case scenario" assuming that workers do not have job rotation (SC1). Therefore, the dose was calculated with the most conservative value of each input (Jayjock et al., 2000), meaning that a hypothetical situation was considered in which everything that contributes to the exposure was maximized: the exposure time $\left(2000 \mathrm{~h} \mathrm{y}^{-1}\right)$ and indoor radon concentration (maximum value). Another scenario was considered assuming an exposure time of 1000 hours in a year to account for time not spent actively at each of the considered workplaces (SC2). In this case, the average of the indoor radon concentration measured in each of the workplaces was used.

\section{Results and discussion}

\subsection{Thermal spas}

The results of the radon concentration measured in the indoor air for each of the studied thermal spas (TSs), as well as the different time durations of the measurements (MT), are presented in Table 1. The indoor radon concentrations range between 73 and $4335 \mathrm{~Bq} \mathrm{~m}^{-3}$, with a geometric mean of $445 \mathrm{~Bq} \mathrm{~m}^{-3}$ and an arithmetic mean of $710 \mathrm{~Bq} \mathrm{~m}^{-3}$.
The radon concentrations cover a wide range of values depending on the different workplaces. Very high levels of radon $\left(>1000 \mathrm{~Bq} \mathrm{~m}^{-3}\right)$ were found in common workplaces of the different TSs, namely the ORL, VS, JS, TP and LP.

In particular, the high radon concentrations detected in most ORLs (143-4335 Bq m$\left.{ }^{-3}\right)$, VSs (112-2873 Bq m $\left.{ }^{-3}\right)$, JSs $\left(1130-1681 \mathrm{~Bq} \mathrm{~m}^{-3}\right)$ and pools in general $\left(73-2808 \mathrm{~Bq} \mathrm{~m}^{-3}\right)$ are directly related to continuous radon emanation from spa water during periods of low ventilation rates. A few anomalies were also detected in BTs $\left(1615 \mathrm{~Bq} \mathrm{~m}^{-3}\right)$ and TAs $\left(1145 \mathrm{~Bq} \mathrm{~m}^{-3}\right)$, although in the latter there is no thermal water usage and the probable radon origin is the subsoil and/or construction materials.

Thermal spas TS1, TS4, TS5 and TS12 are of particular concern due to the presence of very high indoor radon levels, which seems to be in accordance with the high radon potential of the water (Silva and Dinis, 2014, 2015a, 2015b) and the lack of mechanical ventilation. On the other hand, the radon concentrations in thermal spas TS11, TS13 and TS14 are lower due to the presence of mechanical ventilation. Ventilation appears to reduce the accumulation of indoor radon effectively. Concerning the different periods when the indoor radon measurements were taken, during winter the radon levels are considerably higher than during summer, with the exception of TS14 (BT), although the difference is negligible. These results are generally expected due to the better ventilation in the summer. Nevertheless, it turns out that the values of the radon concentration in indoor air fluctuate between higher values in spring and higher values in fall, which reveals the influence of other parameters besides ventilation, as higher indoor radon levels are expected during fall.

The overall results obtained in all thermal spas are presented in Table 2. The values of the indoor radon concentration were grouped into three categories: (i) lower than the EU recommended reference level $\left(300 \mathrm{~Bq} \mathrm{~m}^{-3}\right)$; (ii) higher than the reference level but lower than the national protection threshold (300-400 $\mathrm{Bq} \mathrm{m}^{-3}$ ); and (iii) higher than the national protection threshold (400 $\mathrm{Bq} \mathrm{m}^{-3}$ ).

The category of most concern $\left(>400 \mathrm{Bqm}^{-3}\right)$ includes all TSs with the exception of TS7 and TS13, the latter being the only one with radon levels below the EU recommended value $\left(<300 \mathrm{~Bq} \mathrm{~m}^{-3}\right)$.

\subsection{Workers' homes}

The results of the radon concentration measurements carried out in the interior of the home of a selected worker from each thermal spa are presented in Table 3. Information relating to the period of measurement (season), the thermal spa (TS) from which the worker was selected and the respective workplace (ORL, VP, VS, HS) is included.

The indoor radon concentration within the selected workers' homes ranged between 68 and $4051 \mathrm{~Bq} \mathrm{~m}^{-3}$, with a geometric mean of $410 \mathrm{~Bq} \mathrm{~m}^{-3}$ and an arithmetic average of $785 \mathrm{~Bq} \mathrm{~m}^{-3}$. The results show that the EU reference level is exceeded in several cases, sometimes being much higher in residential environments than in workplaces. The EU reference level was exceeded in approximately $57 \%$ of cases. 
Table 1. Indoor radon concentration in the studied thermal spas.

\begin{tabular}{|c|c|c|c|c|c|c|c|c|c|}
\hline \multirow{2}{*}{ TS } & \multirow{2}{*}{ Location } & \multicolumn{2}{|l|}{ 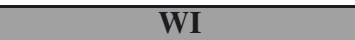 } & \multicolumn{2}{|l|}{ SP } & \multicolumn{2}{|l|}{ SU } & \multicolumn{2}{|l|}{$\mathbf{A U}$} \\
\hline & & ${ }^{222} \operatorname{Rn}\left(B q ~ m^{-3}\right)$ & MT (d) & ${ }^{222} \operatorname{Rn}\left(\mathrm{Bq} \mathrm{m}^{-3}\right)$ & MT (d) & ${ }^{222} \operatorname{Rn}\left(\mathrm{Bq} \mathrm{m}^{-3}\right)$ & MT (d) & ${ }^{222} \operatorname{Rn}\left(B q ~ m^{-3}\right)$ & MT (d) \\
\hline \multirow[t]{3}{*}{1} & $\overline{\mathrm{BT}}$ & 674 & 47 & - & - & 436 & 42 & - & - \\
\hline & ORL & 3479 & & - & & 3119 & & - & \\
\hline & $\mathrm{TP}$ & 784 & & - & & 333 & & - & \\
\hline \multirow[t]{5}{*}{2} & $\mathrm{AC}$ & 566 & 47 & - & - & - & 42 & - & - \\
\hline & ORL & 329 & & - & & 187 & & - & \\
\hline & $\mathrm{TA}$ & 692 & & - & & - & & - & \\
\hline & $\mathrm{TP}$ & 517 & & - & & 267 & & - & \\
\hline & VS & 724 & & - & & 258 & & - & \\
\hline \multirow[t]{5}{*}{3} & ORL & - & - & 502 & 45 & 489 & 41 & - & - \\
\hline & $\mathrm{TA}$ & - & & 401 & & 429 & & - & \\
\hline & $\mathrm{TP}$ & - & & 274 & & 333 & & - & \\
\hline & VP & - & & 453 & & 465 & & - & \\
\hline & VS & - & & 437 & & 495 & & - & \\
\hline \multirow[t]{2}{*}{4} & ORL & - & - & - & - & 4335 & 41 & - & - \\
\hline & VS & - & & - & & 1912 & & - & \\
\hline \multirow[t]{6}{*}{5} & ORL & - & - & - & - & 1190 & 41 & - & - \\
\hline & $\mathrm{RB}$ & - & & - & & 953 & & - & \\
\hline & SH & - & & - & & 878 & & - & \\
\hline & $\mathrm{TP}$ & - & & - & & 2181 & & - & \\
\hline & VP & - & & - & & 1173 & & - & \\
\hline & VS & - & & - & & 1163 & & - & \\
\hline \multirow[t]{5}{*}{6} & BH & - & - & - & - & 1615 & 41 & - & 41 \\
\hline & JS & - & & - & & 1681 & & - & \\
\hline & ORL & - & & - & & 366 & & - & \\
\hline & $\mathrm{TP}$ & - & & - & & 423 & & - & \\
\hline & VS & - & & - & & 1148 & & - & \\
\hline \multirow[t]{2}{*}{7} & ORL & - & - & - & - & 347 & 40 & - & - \\
\hline & VS & - & & - & & 361 & & - & \\
\hline \multirow[t]{2}{*}{8} & ORL & - & - & 169 & 43 & - & - & 143 & 44 \\
\hline & VS & - & & 376 & & - & & 360 & \\
\hline \multirow[t]{3}{*}{9} & ORL & - & - & 169 & 32 & - & - & 269 & 43 \\
\hline & $\mathrm{TP}$ & - & & 121 & & - & & 204 & \\
\hline & VS & - & & 406 & & - & & 229 & \\
\hline \multirow[t]{5}{*}{10} & $\mathrm{AC}$ & 641 & 33 & - & 42 & - & - & 209 & 42 \\
\hline & LP & 1079 & & - & & - & & 377 & \\
\hline & ORL & - & & 255 & & - & & - & \\
\hline & $\mathrm{TA}$ & 481 & & - & & - & & 305 & \\
\hline & $\mathrm{TP}$ & 618 & & - & & - & & 358 & \\
\hline 11 & HS & - & & 116 & 45 & - & - & 132 & 43 \\
\hline & ORL & - & & 312 & & - & & 498 & \\
\hline & $\mathrm{TP}$ & - & & 73 & & - & & 101 & \\
\hline & VS & - & & 112 & & - & & 155 & \\
\hline 12 & JS & - & - & 1130 & 42 & - & - & - & 43 \\
\hline & ORL & - & & 2298 & & - & & 1643 & \\
\hline & TA & - & & 1145 & & - & & - & \\
\hline & $\mathrm{TP}$ & - & & 1494 & & - & & 2808 & \\
\hline & VS & - & & 1971 & & - & & 2873 & \\
\hline 13 & ORL & - & - & 146 & 42 & - & - & 235 & 42 \\
\hline & $\mathrm{TP}$ & - & & 203 & & - & & 176 & \\
\hline & VS & - & & 93 & & - & & 141 & \\
\hline 14 & BT & 172 & 42 & - & - & 266 & 42 & - & - \\
\hline & ORL & 375 & & - & & 175 & & - & \\
\hline & SA & 467 & & - & & 214 & & - & \\
\hline & $\mathrm{TP}$ & 370 & & - & & 240 & & - & \\
\hline & VP & 398 & & - & & 199 & & - & \\
\hline
\end{tabular}


Table 2. Indoor radon concentration values grouped by categories.

\begin{tabular}{|c|c|c|}
\hline$<300 \mathrm{~Bq} \mathrm{~m}^{-3}$ & $300-400 \mathrm{~Bq} \mathrm{~m}^{-3}$ & $>400 \mathrm{~Bq} \mathrm{~m}^{-3}$ \\
\hline TS1 & TS1 & TS1 \\
\hline TS2 & TS2 & TS2 \\
\hline TS3 & TS3 & TS3 \\
\hline- & - & TS4 \\
\hline- & - & TS5 \\
\hline- & TS6 & TS6 \\
\hline- & TS7 & - \\
\hline TS8 & TS8 & TS8 \\
\hline TS9 & - & TS9 \\
\hline TS10 & TS 10 & TS 10 \\
\hline TS11 & TS11 & TS11 \\
\hline- & - & TS12 \\
\hline TS13 & - & - \\
\hline TS14 & TS14 & TS14 \\
\hline
\end{tabular}

Table 3. Indoor radon concentration in the selected worker's dwelling.

\begin{tabular}{lccc}
\hline TS & ${ }^{222} \mathbf{R n}\left(\mathbf{B q ~}^{-3}\right)$ & Season & Workplace \\
\hline 1 & 68 & SU & ORL \\
2 & 254 & SU & ORL \\
3 & 1322 & SU & VP \\
4 & 312 & AU & ORL \\
5 & 1877 & AU & VP \\
6 & 168 & WI & VS \\
7 & 642 & WU & ORL \\
8 & 105 & SU & VS \\
9 & 714 & AU & ORL \\
10 & 4051 & AU & HS \\
11 & 257 & AU & ORL \\
12 & 605 & AU & VP \\
13 & 111 & AU & VS \\
14 & 508 & SU & VP \\
\hline
\end{tabular}

\subsection{Dose assessment}

The effective doses due to radon inhalation were calculated for both considered scenarios (SC1 and SC2) in each of the thermal spas as well as for the workers' homes.

For the thermal spas, the resulting dose ranged between 1.21 and $31.21 \mathrm{mSvy}^{-1}$ for $\mathrm{SC} 1$ and between 0.56 and $15.61 \mathrm{mSv} \mathrm{y}^{-1}$ for SC2 (Table 4). Considering the worst-case scenario, in $36 \%$ of the thermal spas the exposure of the workers is likely to exceed the effective dose of $6 \mathrm{mSv} \mathrm{y}^{-1}$, and this should be considered as a planned exposure situation, according to the European Directive 2013/59/EURATOM.

For the workers' homes, the calculated dose ranged between 1.71 and $102.08 \mathrm{mSv}^{-1}$ (Table 5), which means that in all cases, the annual effective dose was higher than the limit for the general public, $1 \mathrm{mSv}^{-1}$, according to the European Directive 2013/59/EURATOM (although this limit is not applicable in residential conditions). Moreover, in the homes of the workers from TS3, TS7, TS9 and TS10, the annual effective dose was higher than in the respective thermal spa, and in the homes of the workers from TS3, TS5 and TS10, it was higher than $6 \mathrm{mSv}^{-1}$.

For the overall results, a wide variation of the indoor radon concentrations was observed, which is reflected in the calcu-
Table 4. Annual effective dose in thermal spas in different workplaces.

\begin{tabular}{cccc}
\hline TS & Location & $\begin{array}{c}\text { Effective dose SC1 } \\
\left(\mathbf{m S v ~}^{\mathbf{- 1}}\right)\end{array}$ & $\begin{array}{c}\text { Effective dose SC2 } \\
\left(\mathbf{m S v} \mathbf{~}^{-\mathbf{1}}\right)\end{array}$ \\
\hline 1 & ORL & 25.05 & 11.88 \\
& TP & 5.64 & 2.01 \\
2 & ORL & 2.37 & 0.93 \\
& TP & 3.72 & 1.41 \\
3 & VP & 3.35 & 1.65 \\
& ORL & 3.61 & 1.78 \\
4 & ORL & 31.21 & 15.61 \\
5 & ORL & 8.57 & 4.28 \\
6 & ORL & 2.63 & 1.32 \\
7 & ORL & 2.50 & 1.25 \\
8 & ORL & 1.21 & 0.56 \\
9 & TP & 1.47 & 0.59 \\
10 & LP & 7.77 & 2.62 \\
& TP & 4.45 & 1.76 \\
11 & ORL & 3.59 & 1.46 \\
12 & TP & 20.21 & 7.74 \\
13 & ORL & 1.69 & 0.68 \\
14 & ORL & 2.70 & 0.99 \\
& VP & 2.87 & 1.07 \\
\hline
\end{tabular}

Table 5. Annual effective dose in worker's dwellings.

\begin{tabular}{lc}
\hline TS & Effective dose $\left(\mathbf{m S v ~}^{\mathbf{- 1}}\right)$ \\
\hline 1 & 1.71 \\
2 & 6.40 \\
3 & 33.31 \\
4 & 7.86 \\
5 & 47.30 \\
6 & 4.23 \\
7 & 16.18 \\
8 & 2.65 \\
9 & 17.99 \\
10 & 102.08 \\
11 & 6.48 \\
12 & 15.25 \\
13 & 2.80 \\
14 & 12.80 \\
\hline
\end{tabular}

lated annual doses; it is well known that the radon concentration in indoor environments presents a wide variation over time. In addition, there are many intervening factors, which are difficult to control, and will contribute to this variation such as building characteristics, mechanical ventilation and heating systems, water usage, activities of the inhabitants, etc.

In order to determine the long-term average indoor radon concentration (annual), integrated radon measurements should be performed for longer periods (at least for a continuous period of 3 months). Therefore, the values obtained may not be interpreted with respect to the annual average concentration and consequently the annual actual exposure dose, but rather be used to point out how extremely high radon levels, and potentially inhalation doses, may be received by these workers not only in the occupational context but also in their own residential environment. 


\section{Conclusions}

The results showed that the EU reference level of $300 \mathrm{~Bq} \mathrm{~m}^{-3}$ (Directive 2013/59/EURATOM) was exceeded in several cases, sometimes being much higher in residential environments than in workplaces (as can be observed in TS10 and the respective worker's home, for example), and this may be worrisome. The results also showed some variations related to the occupation of the space and ventilation, as well as the influence of geological settings.

For the worst-case scenario, in $36 \%$ of the thermal spas the exposure of the workers is likely to exceed the effective dose of $6 \mathrm{mSv}^{-1}$. However, when considering the exposure scenario with job rotation and average indoor radon concentrations, this reference level will be exceeded in approximately $21 \%$ of the thermal spas.

According to the results and the European Directive 2013/59/EURATOM reference levels, some recommendations may be proposed in order to optimize the workers' exposure. In general, a system of surveillance, monitoring and radiation protection of workers should be implemented which should include, besides other measures: the use of individual protection equipment, such as masks (when justified); and implementation of job rotation and improvement of ventilation conditions within the thermal spa facilities, providing an effective ventilation system for all workplaces. In addition, workers should be informed how to improve their home's ventilation with simple actions such as opening doors and windows. In the most serious cases, architectural and constructive solutions should be adopted in order to reduce the building's contact with the ground and/or isolation measures against radon exhalation should be implemented.

\section{References}

Antão A.M. (2014) Assessment of radon concentrations inside a high school building in Guarda (Portugal): legislation implications and mitigation measures proposed, Procedia Earth and Planetary Science 8, 7-12.

Carvalho J.M. (1996) Mineral water exploration and exploitation at the Portuguese Hercynian Massif, Environmental Geology 27, 252-258.

Gray A., Read S., McGale P., Darby S. (2009) Lung cancer deaths from indoor radon and the cost effectiveness and potential of policies to reduce them, $B M J \mathbf{3 3 8}, 3110$.

ICRP (1994) International Commission Radiological Protection. Protection against ${ }^{222} \mathrm{Rn}$ at home and at work. http://www. icrp.org/docs/ICRP_Statement_on_Radon_AND_Lung_cancer_ risk_from_radon_and_progeny(for_cconsultation).pdf.
Jayjock M.A., Lynch J.R., Nelson D.I. (2000) Risk Assessment Principles for Hygienist, American Industrial Hygiene Association. AIHA Press, Fairfax.

Kobeissi M.A., El Samad O., Zahraman K., Rachid I. (2014) Assessment of Indoor and Outdoor Radon Levels, International Journal of Disaster Risk Science 214, 214-226.

Madureira J., Paciência I., Rufo J., Moreira A., de Oliveira Fernandes E., Pereira A. (2016) Radon in indoor air of primary schools: determinant factors, their variability and effective dose, Environ. Geochem. Health 38, 523-533.

OMS (2007) Radon and cancer. Fact Sheet Nr. 291. WHO, Geneve.

Radosys (2000) User's Manual. http://fgmambiente.it/wp-content/ uploads/2014/03/Manuale-Radosys-RSV10.pdf.

Silva A.S., Dinis M.L. (2014) Avaliação da concentração de radão na água mineral natural de spas termais portugueses, I Jornadas Saúde Ocupacional.

Silva A.S., Dinis M.L. (2015a) Avaliação da Concentração de Radão na Água Mineral Natural de Spas Termais Portugueses. In: Occupational Safety and Hygiene (P. Arezes, J.S. Baptista, M. Barroso, P. Carneiro, P. Cordeiro, N. Costa, R. Melo, A.S. Miguel, G. Perestrelo, Eds.) pp.59-65. Taylor \& Francis, London.

Silva A.S., Dinis M.L. (2015b) The presence of radon in thermal spas and their occupational implications - a review. In: Occupational Safety and Hygiene III (P. Arezes, J.S. Baptista, M. Barroso, P. Carneiro, P. Cordeiro, N. Costa, R. Melo, A.S. Miguel, G. Perestrelo, Eds.) pp. 353-355. Taylor \& Francis, London.

Silva A.S., Dinis M.L. (2016) Measurements of indoor radon and total gamma dose rate in Portuguese thermal spas. In: Occupational Safety and Hygiene IV (P. Arezes, J.S. Baptista, M. Barroso, P. Carneiro, P. Cordeiro, N. Costa, R. Melo, A.S. Miguel, G. Perestrelo, Eds.) pp. 485-489. Taylor \& Francis, London.

Silva A.S., Dinis M.L., Diogo M.T. (2013) Occupational Exposure to Radon in Thermal Spas, Occupational Safety and Hygiene (P. Arezes, J.S. Baptista, M. Barroso, P. Carneiro, P. Cordeiro, N. Costa, R. Melo, A.S. Miguel, G. Perestrelo, Eds.) pp. 273-277. Taylor \& Francis, London.

Silva A.S., Dinis M.L., Fiúza A. (2014) Research on Occupational Exposure to Radon in Portuguese Thermal Spas. In: Occupational Safety and Hygiene II (P. Arezes, J.S. Baptista, M. Barroso, P. Carneiro, P. Cordeiro, N. Costa, R. Melo, A.S. Miguel, G. Perestrelo, Eds.), pp. 273 -277. Taylor \& Francis, London.

Silva A.S., Dinis M.L., Pereira A.J.S.C., Fiúza A. (2016) Radon levels in Portuguese thermal spas. RAD Journal 1, 76-80.

UNSCEAR (2000) Publication E.00.IX.3. Sources and Effects of Ionizing Radiation, United Nations, New York.

WHO (2009) Handbook on indoor radon: a public health perspective (H. Zeeb, F. Shannoun, Eds.).

Cite this article as: A.S. Silva, M.L. Dinis, A.J.S.C. Pereira. Assessment of indoor radon levels in Portuguese thermal spas. Radioprotection 51(4), 249-254 (2016). 